\title{
BIONANOCOMPÓSITOS HÍBRIDOS FORMADOS POR HIDROGÉIS DE POLISSACARÍDEO E NANOARGILA: II. INCORPORAÇÃO EM SUBSTRATO PARA MELHORARIA DE MUDAS
}

\author{
Uilian Gabaldi Yonezawa ${ }^{1}$, Marcia Regina de Moura $^{2}$, Fauze Ahmad Aouada ${ }^{2 *}$ \\ ${ }^{1}$ Doutorando no Programa de Pós-Graduação em Ciência dos Materiais, Universidade Estadual Paulista \\ (UNESP), Faculdade de Engenharia, Câmpus de Ilha Solteira - SP. \\ ${ }^{2}$ Professor(a) do Departamento de Física e Química, Universidade Estadual Paulista (UNESP), Faculdade de \\ Engenharia, Câmpus de Ilha Solteira - SP.*E-mail: faouada@yahoo.com.br
}

RESUMO: O objetivo deste trabalho foi testar o efeito de hidrogel biodegradável (composto por $6 \% \mathrm{~m} / \mathrm{v}$ de acrilamida e $1 \% \mathrm{~m} / \mathrm{v}$ de carboximetilcelulose) e seus bionanocompósitos contendo diferentes concentrações de nanoargila $(0-20 \% \mathrm{~m} / \mathrm{v})$ incorporados em um substrato de cultivo utilizado para germinação e desenvolvimento de mudas de alface (Lactuca sativa). Os experimentos foram conduzidos com um delineamento inteiramente casualizado. $\mathrm{O}$ primeiro experimento estudou doses crescentes de hidrogel incorporado no substrato. O segundo experimento avaliou os bionanocompósitos com crescentes concentrações de nanoargila. Os parâmetros analisados foram índice de velocidade de germinação, porcentagem de germinação, diâmetro do caule, massa fresca e seca, tamanho da raiz e alturas das partes aérea e total da planta. No primeiro experimento, notou-se que a aplicação de 5\% foi a que apresentou os melhores resultados na germinação e o desenvolvimento do cultivo de alface. As aplicações dos bionanocompósitos demonstraram resultados positivos em todos os parâmetros analisados, causando também um melhor desenvolvimento do sistema radicular (segundo experimento). Sendo que os bionanocompósitos contendo 20\% de nanoargila foram os mais promissores. Portanto, os hidrogéis e os bionanocompósitos otimizam a germinação da hortaliça Lactuca sativa, demonstrando ser um produto promissor para a aplicação na agricultura.

Palavras-chave: Lactuca sativa. Hidrogel. Substrato. Agricultura.

\section{HYBRID BIONANOCOMPOSITES FORMED FROM POLYSACCHARIDE HYDROGELS AND NANOCLAY: II. INCORPORATION IN SUBSTRATE TO SEEDLING IMPROVING}

\begin{abstract}
The objective of this work was to test the effect of biodegradable hydrogel (formed from $6 \mathrm{wt}-\%$ of acrylamide and $1 \mathrm{wt}-\%$ of carboxymethylcellulose) and their bionanocomposites with different nanoclay concentrations (0-20 wt-\%) incorporated in a cultivation substrate used in germination and development of lettuce seedlings (Lactuca sativa). The experiments were conducted in a randomized design. In the first experiment, it was studied different hydrogel amount added in the substrate. In the second experiment, it was evaluated bionanocomposites containing different nanoclay concentration. The
\end{abstract}

Cultura Agronômica, Ilha Solteira, v.26, n.1, p.82-94, 2017 
parameters analyzed were germination rate index, germination percentage, stalk diameter, fresh and dry weights, root size and heights of the root and total plant. In the first experiment, it was possible to note that best results of germination and development of lettuce cultivation were found to $5 \%$ hydrogel. The application of bionanocomposites had positive results in all parameters, including an improvement in root development, mainly in bionanocomposites with highest nanoclay amount. Therefore, the hydrogels and the bionanocomposites optimized the germination of Lactuca sativa vegetable, showing to be a promising product for the application in agriculture.

Key words: Lactuca sativa. Hydrogel, Substrate. Agriculture.

\section{INTRODUÇÃO}

A necessidade de aumentar a produção e a busca por qualidade no ramo agronômico tem incentivado os produtores a minimizar custos e buscar melhores técnicas de produção sem causar danos ao meio ambiente. Atualmente, um dos principais problemas na agricultura é a escassez dos recursos naturais, causando um aumento na dependência de fertilizantes e dos recursos hídricos (MENDONÇA et al., 2013). Neste contexto o uso do hidrogel como condicionador de solo e substrato contribui para aumentar a retenção de água, reduzir a frequência de irrigação, melhorar a aeração do solo, e acelerar o desenvolvimento radicular e aéreo da planta, melhorando a produção e qualidade de mudas (AZEVEDO et al., 2002 e FONTENO; BILDERBAK, 1993). O hidrogel pode atuar também como um veículo carreador em sistema de liberação controlada, possibilitando uma maior absorção de alguns nutrientes, prolongando a sua dissolução, o que contribui para uma melhor fertilidade do solo (LIU et al., 2012).

Muitos estudos relacionados com a aplicação de hidrogéis na agricultura para diversas culturas (horticultura, fruticultura e produção de mudas de diversas espécies) têm sido relatados (NAVROSKI et al., 2015; HAFLE et al., 2008; AKHTEEL et al., 2004). Por exemplo, segundo Fan et al. (2015), a incorporação do hidrogel no substrato elevou a taxa de germinação do cultivar de espinafre, incluindo a altura da planta, diâmetro do caule, massas fresca e seca da parte aérea e raízes.

O uso de um hidrogel comercial (Hydroplan-EB ${ }^{\circledR}$ ) adicionado ao substrato (Bioterra ${ }^{\circledR}$ ) proporcionou um melhor desenvolvimento das mudas de pimentão devido à maior disponibilidade de água, contribuindo também para um aumento da massa seca da parte aérea e do número de folhas (MARQUES; BARTOS, 2010). A adição de hidrogel no substrato de cultivo, juntamente com uma solução de fertilizante para o cultivar de tomate e alface provocou um crescimento das raízes com o aumento das doses do polímero (AZEVEDO et al., 2002). Portanto, o uso do hidrogel pode melhorar as propriedades físico-químicas do solo e certamente contribuirá também para melhoria das propriedades de um determinado cultivo em contato.

Cultura Agronômica, Ilha Solteira, v.26, n.1, p.82-94, 2017 
O objetivo deste trabalho foi estudar o efeito de diferentes dosagens de hidrogel biodegradável e seus bionanocompósitos contendo diferentes concentrações de nanoargila em um substrato na germinação e no desenvolvimento do cultivo de alface (Lactuca sativa).

\section{MATERIAL E MÉTODOS}

\section{Primeiro experimento: aplicação do hidrogel constituídos por poliacrilamida (PAAm) e carboximetilcelulose (CMC)}

O experimento foi conduzido em Ilha Solteira (SP), na área externa do laboratório de Química do DFQ-UNESP, no período de maio a junho de 2015. Após a semeadura com as primeiras plantas germinadas, a bandeja de poliestireno foi colocada ao sol em um período diário de 10 horas. A partir das 17h30min a bandeja foi recolhida e acondicionada no interior do laboratório. Isto se procedeu durante 20 dias.

Para o estudo da produção de muda foi utilizada semente comercial de alface (Lactuca sativa), com pureza de $100 \%$ e porcentagem de germinação de $98 \%$. O substrato utilizado foi o Bioplant ${ }^{\circledR}$, composto por: casca de pinus, esterco, serragem, fibra de coco, vermiculita, casca de arroz, cinza, gesso agrícola, carbonato de cálcio, magnésio, termofosfato magnesiano (yoorin) e aditivos (fertilizantes) (dados fornecidos pelo fabricante). Este substrato, de acordo com o fabricante, apresenta densidade de $260 \mathrm{~kg} / \mathrm{m}^{3}, \mathrm{pH}$ de $6,2( \pm 0,5)$ e capacidade de retenção de água de 55\%. Foi utilizada uma bandeja de poliestireno com 200 células. O hidrogel foi sintetizado com poliacrilamida (PAAm) e carboximetilcelulose (CMC) de acordo com o procedimento descrito por Aouada et al. (2009) (parte I desse trabalho).

Antes do preenchimento da bandeja de poliestireno, o substrato foi seco em estufa a 60 ${ }^{\circ} \mathrm{C}$ por no mínimo 24 horas. Após o hidrogel ser sintetizado e purificado em água destilada durante 5 dias, o mesmo foi triturado e seco em estufa a $40{ }^{\circ} \mathrm{C}$. Em seguida, diferentes doses de hidrogel ( $0 \%$ como controle; $0,125 \% ; 1 \% ; 2 \% ; 3 \%$ e $5 \%$ em relação ao substrato) foram previamente intumescidos em $250 \mathrm{~mL}$ de água destilada e incorporados em $15 \mathrm{~g}$ de substrato seco.

A irrigação das mudas foi efetuada uma vez ao dia (08h00min), utilizando $10 \mathrm{~mL}$ de água destilada por célula. As mudas permaneceram durante um período de 20 dias ao sol. $\mathrm{O}$ experimento foi conduzido com um delineamento inteiramente casualizado, com 6 tratamentos e 5 repetições $(n=5)$ para cada tratamento. Em cada tratamento foi semeada uma semente com profundidade de $1 \mathrm{~cm}$, totalizando 30 sementes.

\section{Segundo experimento: aplicação do bionanocompósito contendo diferentes concentrações de nanoargila}

A metodologia utilizada foi à mesma da primeira aplicação descrita no primeiro experimento, sendo realizada no período de junho a julho de 2015, sofrendo algumas alterações a fim de testar hidrogéis com diferentes concentrações de nanoargila para melhorar a qualidade e germinação das mudas. As alterações consistem na aplicação de $5 \%$ de 
bionanocompósitos incorporado ao substrato, sintetizados com diferentes concentrações de nanoargila $(0,10$ e $20 \% \mathrm{~m} / \mathrm{v})$ (parte I desse trabalho). O experimento também foi conduzido com um delineamento inteiramente casualizado, com 4 tratamentos e 10 repetições $(n=10)$ para cada tratamento.

\section{Parâmetros avaliados}

A qualidade das mudas submetidas a diferentes dosagens de hidrogel incorporado ao substrato foi avaliada depois de 20 dias após a germinação, através dos parâmetros: altura total da planta; diâmetro do caule; número de folhas; comprimentos da parte aérea (do colo até a última folha) e da raiz (do colo até a última raiz); massas fresca e seca total; porcentagem de germinação e índice de velocidade de germinação.

O diâmetro do caule na altura do substrato foi medido com auxílio de um paquímetro digital, da marca Mitutoyo, com precisão de $0,001 \mathrm{~mm}$. O comprimento da parte aérea foi obtido com auxílio de uma régua graduada, medindo-se desde o colo da muda até a última folha. Em seguida, o substrato foi retirado do sistema radicular com auxílio de água destilada, e determinado a altura total da planta com uma régua graduada, a partir da última folha da planta até o fim da última raiz emitida. O comprimento do sistema radicular também foi medido com auxílio de uma régua, medindo-se do colo da muda até o fim da última raiz emitida. A massa fresca foi obtida com a pesagem da muda em uma balança analítica, e posteriormente a secagem da mesma em estufa a $60^{\circ} \mathrm{C}$ em temperatura controlada, até a obtenção da massa seca (constante) e novamente a pesagem do material em balança analítica.

A porcentagem de germinação, depois de 23 dias após a semeadura, foi quantificada através da equação:

$$
\mathrm{Gp}=\frac{\mathrm{Ng}}{\mathrm{Ns}} \cdot 100
$$

onde Gp é porcentagem de germinação; $\mathrm{Ng}$ é o número de plantas germinadas e Ns é o número de sementes semeadas.

O índice de velocidade de germinação (equação 2) foi calculado segundo a fórmula proposta por Maguire (1962). A primeira contagem das plantas normais foi realizada após três dias e a contagem final aos sete dias. As avaliações foram diárias até o $7^{\circ}$ dia após a semeadura.

$$
I V G=\frac{G 1}{N 1}+\frac{G 2}{N 2}+\frac{G 3}{N 3}+\frac{G n}{N n}
$$

Onde IVG é o índice de velocidade de germinação; G é o número de plantas emergidas de cada dia e $\mathrm{N}$ é número de dias de semeadura até a respectiva contagem.

Os resultados experimentais foram submetidos a análise de variância (ANOVA) empregando teste de Tukey com nível de confiança de $95 \%$ no programa Minitab ${ }^{\circledR}$.

Cultura Agronômica, Ilha Solteira, v.26, n.1, p.82-94, 2017 


\section{RESULTADOS E DISCUSSÃO}

\section{Primeiro experimento}

Com a aplicação do hidrogel, observou-se que após 3 dias de semeadura, as primeiras germinações de sementes de alface apresentaram resultados positivos com 5\% de hidrogel incorporado no substrato com relação às demais quantidades testadas. Portanto, a presença do hidrogel melhorou a eficiência da germinação da semente.

Após 23 dias da semeadura, observou-se que diferentes dosagens de hidrogel proporcionaram respostas diferentes das mudas produzidas em bandeja poliestireno (200 células) para as variáveis: porcentagem de germinação (Figura 1a) e índice de velocidade de germinação (Figura 1b).

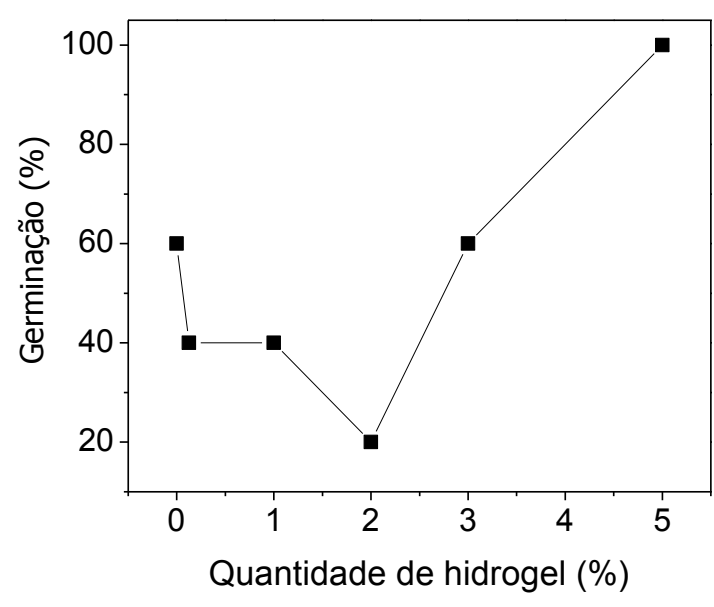

(a)

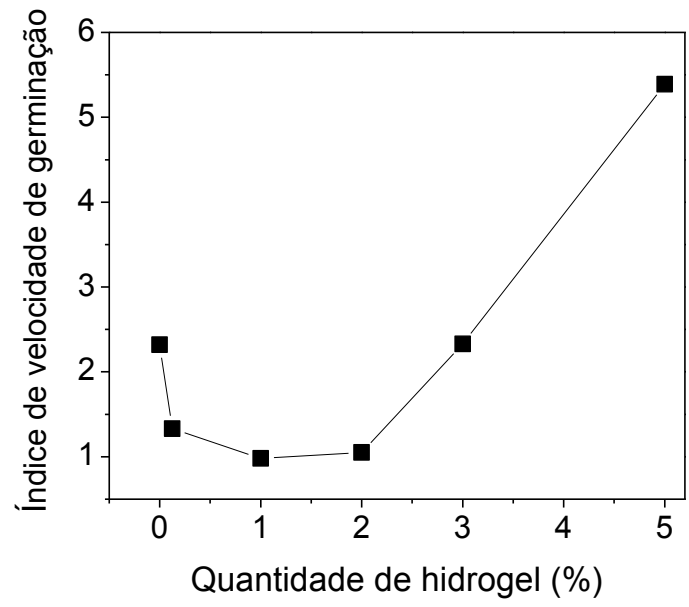

(b)

Figura 1. (a) Porcentagem de germinação e (b) índice da velocidade de germinação em função de diferentes quantidades de hidrogéis sintetizados com PAAm e CMC.

Pode-se observar na Figura 1, que pequenas quantidades de hidrogel $(0,125$ a $2 \%)$ prejudicam a germinação e o índice de velocidade de germinação. Segundo Navroski et al. (2015), a porosidade de um substrato é o espaço onde água, raiz e ar estão presentes. A porosidade pode ser classificada em macroporos, que é o espaço entre os agregados do substrato, e microporos, que é o espaço dentro dos agregados. Tais autores descrevem também que a porosidade deve apresentar um bom equilíbrio entre os macroporos (retém o ar) e os microporos (retém água). Portanto, nessas composições, os hidrogéis podem estar ocupando os macroporos prejudicando a circulação de ar (aeração) no meio do substrato. Por outro lado, observou aumento significativo, tanto na porcentagem de germinação como no índice de velocidade de germinação, para concentrações acima de $2 \%$. Além disso, a concentração de $5 \%$ demonstrou ser a melhor no processo germinativo da alface (Lactuca sativa) (germinação de $100 \%$ ). Isto pode estar relacionado com a maior disponibilidade de água, maior expansão do substrato, maior porosidade e menor densidade, causada pela presença do hidrogel. Vale ressaltar que de acordo com a literatura, doses elevadas de hidrogel podem prejudicar a 
germinação e o desenvolvimento do sistema radicular, pois proporciona umidade excessiva ao substrato (HAFLE et al., 2008; MOREIRA et al., 2010; SOUSA et al., 2013). Segundo Hafle et al. (2008) observou que doses acima de 4,5 g/L de hidrogel (Ecogel VEG ${ }^{\circledR}$ ) incorporado ao substrato para produção de mudas de maracujazeiro doce, interferem negativamente no enraizamento e no desenvolvimento das mudas, devido ao excesso de água disponível no meio da cultura.

Por outro lado, quando aplicada à dosagem ideal resultados positivos podem ser observados. Albuquerque Filho et al. (2009) estudaram as características vegetativas do coentro submetidas a diferentes doses de polímero hidroabsorvente (Hidratassolo ${ }^{\circledR}$ ) e lâminas de irrigação, as análises em maior lâmina demonstraram que o emprego do polímero com doses na faixa de 6 a $11 \mathrm{dg} / \mathrm{kg}$ proporcionou melhores resultados e a dose máxima de $16 \mathrm{dg} / \mathrm{kg}$ evidenciou uma queda em relação à testemunha. Portanto, o uso do hidrogel em altas quantidades pode prejudicar o desenvolvimento das plantas. Por isto, a importância de se determinar a dose ideal a ser aplicada.

Pode se observar que os parâmetros analisados com relação à massa fresca total (MFT) e o número de folhas (NF) apresentaram tendência positiva com a aplicação de $5 \%$ dos hidrogéis de PAAm e CMC incorporados ao substrato com relação ao controle (Tabela 1). Isto pode estar relacionado ao fato de haver maior disponibilidade de água na presença de maiores doses de hidrogéis.

Tabela 1. Valores dos parâmetros analisados para as diferentes concentrações de hidrogéis de PAAm e CMC. Altura total (AT), altura da parte aérea (APA), tamanho da raiz (TR), massa fresca total (MFT), massa seca total (MST), diâmetro do caule (DC) e número de folhas (NF).

\begin{tabular}{|c|c|c|c|c|c|c|c|}
\hline $\begin{array}{c}\text { Hidrogel } \\
(\%)\end{array}$ & $\mathrm{AT}(\mathbf{c m})$ & $\operatorname{APA}(\mathbf{c m})$ & TR (cm) & MFT (g) & MST (g) & DC (mm) & NF \\
\hline $\mathbf{0}$ & $10,6 \pm 1,2^{\mathrm{a}}$ & $4,1 \pm 0,6^{\mathrm{a}}$ & $6,5 \pm 0,6^{\mathrm{a}}$ & $0,05 \pm 0,01^{\mathrm{a}}$ & $0,0035 \pm 0,0014^{\mathrm{a}}$ & $0,660 \pm 0,036^{\mathrm{a}}$ & $3,3 \pm 0,6^{\mathrm{a}}$ \\
\hline 0,125 & $9,0 \pm 2,8^{\mathrm{a}}$ & $3,7 \pm 1,7^{\mathrm{a}}$ & $5,3 \pm 1,1^{a}$ & $0,05 \pm 0,04^{\mathrm{a}}$ & $0,0031 \pm 0,0160^{\mathrm{a}}$ & $0,723 \pm 0,058^{\mathrm{a}}$ & $3,5 \pm 0,7^{\mathrm{a}}$ \\
\hline 1 & $8,8 \pm 1,1^{\text {a }}$ & $3,1 \pm 0,9^{\mathrm{a}}$ & $5,7 \pm 0,1^{\mathrm{a}}$ & $0,04 \pm 0,02^{\mathrm{a}}$ & $0,0021 \pm 0,0009^{\mathrm{a}}$ & $0,670 \pm 0,085^{a}$ & $3,5 \pm 0,7^{\mathrm{a}}$ \\
\hline 2 & $10,9 \pm 0^{\mathrm{a}}$ & $3,5 \pm 0^{\mathrm{a}}$ & $7,4 \pm 0^{\mathrm{a}}$ & $0,07 \pm 0,02^{\mathrm{a}}$ & $0,0039 \pm 0^{\mathrm{a}}$ & $0,651 \pm 0^{\mathrm{a}}$ & $3,0 \pm 0^{\mathrm{a}}$ \\
\hline 3 & $10,2 \pm 1,5^{\mathrm{a}}$ & $3,8 \pm 0,1^{\mathrm{a}}$ & $5,8 \pm 1,0^{\mathrm{a}}$ & $0,07 \pm 0,02^{\mathrm{a}}$ & $0,0037 \pm 0,0011^{\mathrm{a}}$ & $0,650 \pm 0,036^{\mathrm{a}}$ & $3,6 \pm 0,6^{\mathrm{a}}$ \\
\hline 5 & $8,5 \pm 3,5^{\mathrm{a}}$ & $3,9 \pm 0,4^{\mathrm{a}}$ & $4,6 \pm 0,9^{a}$ & $0,07 \pm 0,01^{\mathrm{a}}$ & $0,0035 \pm 0,0005^{\mathrm{a}}$ & $0,655 \pm 0,017^{\mathrm{a}}$ & $3,8 \pm 0,4^{\mathrm{a}}$ \\
\hline valor-p* & 0,354 & 0,828 & 0,094 & 0,419 & 0,655 & 0,486 & 0,761 \\
\hline
\end{tabular}

Cultura Agronômica, Ilha Solteira, v.26, n.1, p.82-94, 2017 
Segundo Azevedo et al. (2015), a aplicação da dose ideal de hidrogel incorporado ao substrato no cultivo de clones de eucalipto (VM01 e AEC0144) apresentaram resultados promissores. No clone VM01 todos os parâmetros analisados foram influenciados positivamente pela presença do hidrogel, cuja, a dose recomendada foi de 1,5 g/L e no clone AEC0144, apenas os parâmetros do comprimento médio da raiz, sobrevivência das miniestacas e enraizamento das miniestacas foram influenciados pelo polímero com dosagem de 1,0 g/L. Portanto, a utilização do polímero incorporado ao substrato é uma alternativa promissora, pois possibilita um aumento na porosidade total, não afeta a disponibilidade hídrica e proporciona aumento do volume de água de reserva do substrato, favorecendo o melhor desempenho das plantas.

Vale ressaltar que apesar da concentração de 5\% de hidrogel ter apresentado o resultado de menor tamanho de raiz, a mesma apresentou um maior número de ramificações com relação ao controle, pois o sistema radicular da planta cresceu na direção do hidrogel inserido no substrato.O que proporcionou maior superfície de contato entre a raiz com a fonte de água facilitando a formação desta e sua absorção (BARBOSA et al., 2013). Hutterman et al. (1999) observaram que além de um maior desenvolvimento da cultura na presença de hidrogel, o sistema radicular, apresentou um maior número de raízes. Já Navroski et al. (2015) relataram que as maiores doses de hidrogel aplicadas no crescimento de Eucalyptus dunnii, proporcionaram maior massa de raízes e maior formação das mesmas, provavelmente devido à maior disponibilidade de água.

Portanto, no nosso trabalho, a aplicação de 5\% de hidrogel com relação ao substrato no plantio de alface melhorou a germinação e o desenvolvimento da quantidade de raízes da planta, sendo que os demais parâmetros analisados não diferiram estatisticamente (Tabela 1), o que proporciona maior desenvolvimento, crescimento e sobrevivência da mesma em campo.

\section{Segundo experimento}

Como dito anteriormente a quantidade de hidrogel utilizada foi determinada a partir da investigação dos parâmetros referente à aplicação dos hidrogéis sintetizados com poliacrilamida (PAAm) e polissacarídeo (CMC) (primeiro experimento). Portanto, a quantidade utilizada para a aplicação foi de 5\% com relação ao substrato. Após essa primeira investigação, iniciaram-se os estudos com nanoargila (bionanocompósitos). Observou-se após 3 dias de semeadura, que a presença de nanoargila na matriz polimérica proporcionou resultados positivos na germinação de sementes de alface, sendo que, o bionanocompósito sintetizado com $20 \%$ de nanoargila incorporado no substrato demonstrou o melhor desempenho com relação aos demais tratamentos analisados.

Foi observado também que após 23 dias de semeadura, os bionanocompósitos sintetizados com diferentes concentrações de nanoargila proporcionaram aumento significativo na porcentagem de germinação (Figura 2a) e no índice de velocidade de germinação (Figura 2b). Para os demais parâmetros analisados, os resultados da aplicação dos bionanocompósitos sintetizados com $20 \%$ de nanoargila indicaram um incremento em relação 
ao controle, hidrogel puro e o bionanocompósito sintetizado com 10\% de nanoargila. Podese observar ainda que o número de folhas para esse bionanocompósito aumentou em relação ao controle (Tabela 2). As significâncias desses resultados foram estatisticamente comprovadas pela análise de variância seguindo o teste de Tukey.

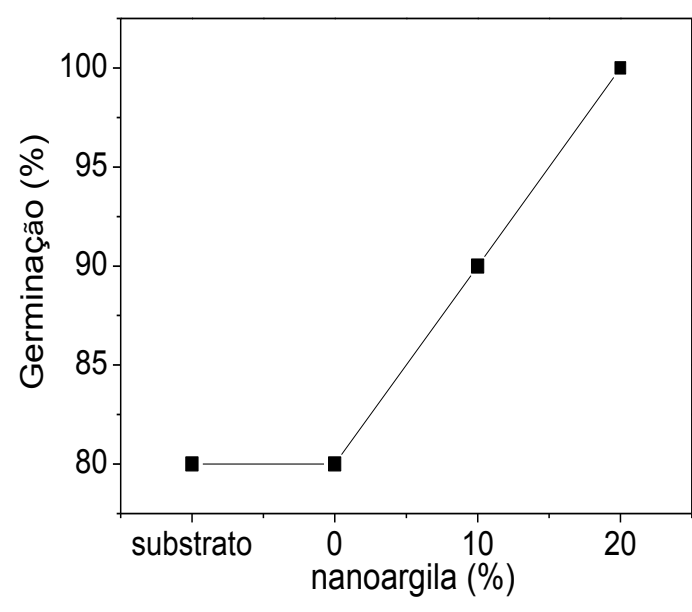

(a)

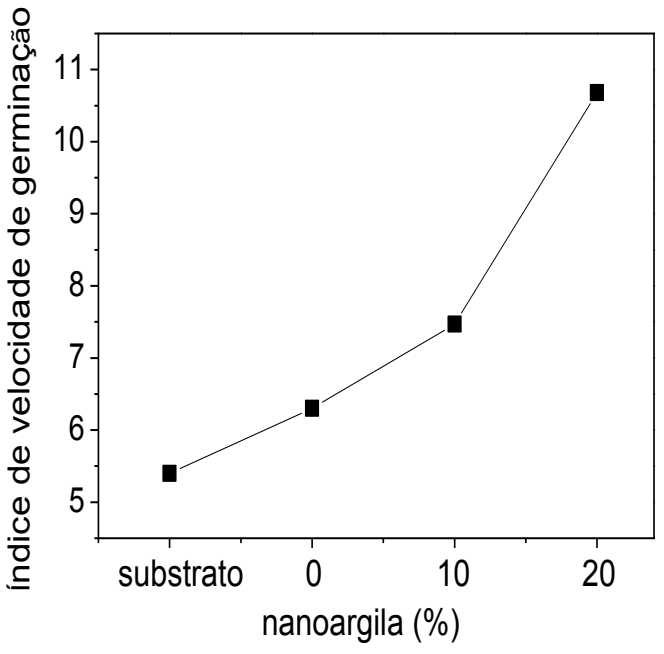

(b)

Figura 2. (a) Porcentagem germinação (\%) e (b) índice de velocidade de germinação em função de diferentes concentrações de nanoargila.

Tabela 2. Valores dos parâmetros analisados dos bionanocompósitos com diferentes concentrações de nanoargila.

\begin{tabular}{|c|c|c|c|c|c|}
\hline & $\begin{array}{l}\text { Substrato } \\
\text { (controle) }\end{array}$ & Hidrogel $0 \%$ & Hidrogel $10 \%$ & Hidrogel $20 \%$ & valor-p* \\
\hline $\begin{array}{l}\text { Altura total da } \\
\text { planta }(\mathrm{cm})\end{array}$ & $9,41 \pm 0,58^{a, b}$ & $8,43 \pm 0,64^{\mathrm{a}}$ & $8,42 \pm 1,29^{a}$ & $10,21 \pm 0,93^{b}$ & 0,007 \\
\hline $\begin{array}{c}\text { Altura da parte } \\
\text { aérea da planta }(\mathrm{cm})\end{array}$ & $2,10 \pm 0,19^{a}$ & $2,00 \pm 0,18^{a}$ & $2,10 \pm 0,35^{a}$ & $2,60 \pm 0,37^{b}$ & 0,004 \\
\hline $\begin{array}{c}\text { Tamanho da raiz } \\
(\mathbf{c m})\end{array}$ & $7,33 \pm 0,65^{a}$ & $6,26 \pm 0,49^{a}$ & $6,48 \pm 0,75^{a}$ & $7,44 \pm 0,67^{a}$ & 0,020 \\
\hline Massa fresca (g) & $0,11 \pm 0,01^{a}$ & $0,11 \pm 0,02^{a}$ & $0,09 \pm 0,05^{\mathrm{a}}$ & $0,16 \pm 0,03^{b}$ & 0,001 \\
\hline Massa seca (g) & $0,0076 \pm 0,0007^{\mathrm{a}}$ & $0,0078 \pm 0,0017^{\mathrm{a}}$ & $0,0061 \pm 0,0030^{a}$ & $0,0106 \pm 0,0017^{b}$ & 0,003 \\
\hline $\begin{array}{l}\text { Medida do caule } \\
\text { (mm) }\end{array}$ & $0,93 \pm 0,04^{\mathrm{a}, \mathrm{b}}$ & $0,95 \pm 0,12^{a, b}$ & $0,84 \pm 0,07^{a}$ & $0,99 \pm 0,06^{b}$ & 0,011 \\
\hline Número de folhas & $4 \pm 0^{a}$ & $4 \pm 0^{\mathrm{a}}$ & $4,1 \pm 0,3^{\mathrm{a}, \mathrm{b}}$ & $4,4 \pm 0,5^{b}$ & 0,040 \\
\hline
\end{tabular}

Médias, com seus respectivos valores de desvios padrões, seguidas de letras diferentes diferem estatisticamente entre si seguindo o teste de Tukey com nível de confiança de $95 \%$ * Ao comparar o valor-p para o nível de confiança de $95 \%$, a hipótese nula pode ser excluída, confirmando a diferença estatística entre os parâmetros avaliados.

Cultura Agronômica, Ilha Solteira, v.26, n.1, p.82-94, 2017 
Tais resultados podem estar relacionados ao fato do bionanocompósito proporcionar uma disponibilidade de água mais controlada, mantendo o meio de cultivo, ou seja, o substrato com umidade constante, por um período de tempo maior. Outro fator é a alta capacidade de troca iônica que os bionanocompósitos possuem com o aumento de nanocargas de argila na matriz do polímero. Além disso, a nanoargila pode atuar como barreira para um controle de liberação. De acordo com Bortolin et al. (2013), altas concentrações de montmorilonita na matriz polimérica de hidrogéis de poliacrilamida e metilcelulose garantem alta capacidade de troca iônica, permitindo o carregamento e liberação de altas quantidades de nutrientes. Segundo esses autores, o argilomineral atua também como barreira no controle de liberação, o que possibilita um tempo maior para o processo de dessorção de nutrientes. Portanto a presença de nanoargila na matriz dos hidrogéis estudados aqui pode reduzir a lixiviação de nutriente presente no substrato durante o processo de rega, proporcionando uma melhor disponibilidade de nutrientes no meio de cultivo, através da liberação controlada do mesmo.

Além disso, a incorporação dos bionanocompósitos no substrato influenciou positivamente no desenvolvimento (Figura 3) e no sistema radicular das mudas de alface (Figura 4a). Foram observadas também pequenas quantidades de hidrogel fixados nas raízes das mudas (Figura 4b).

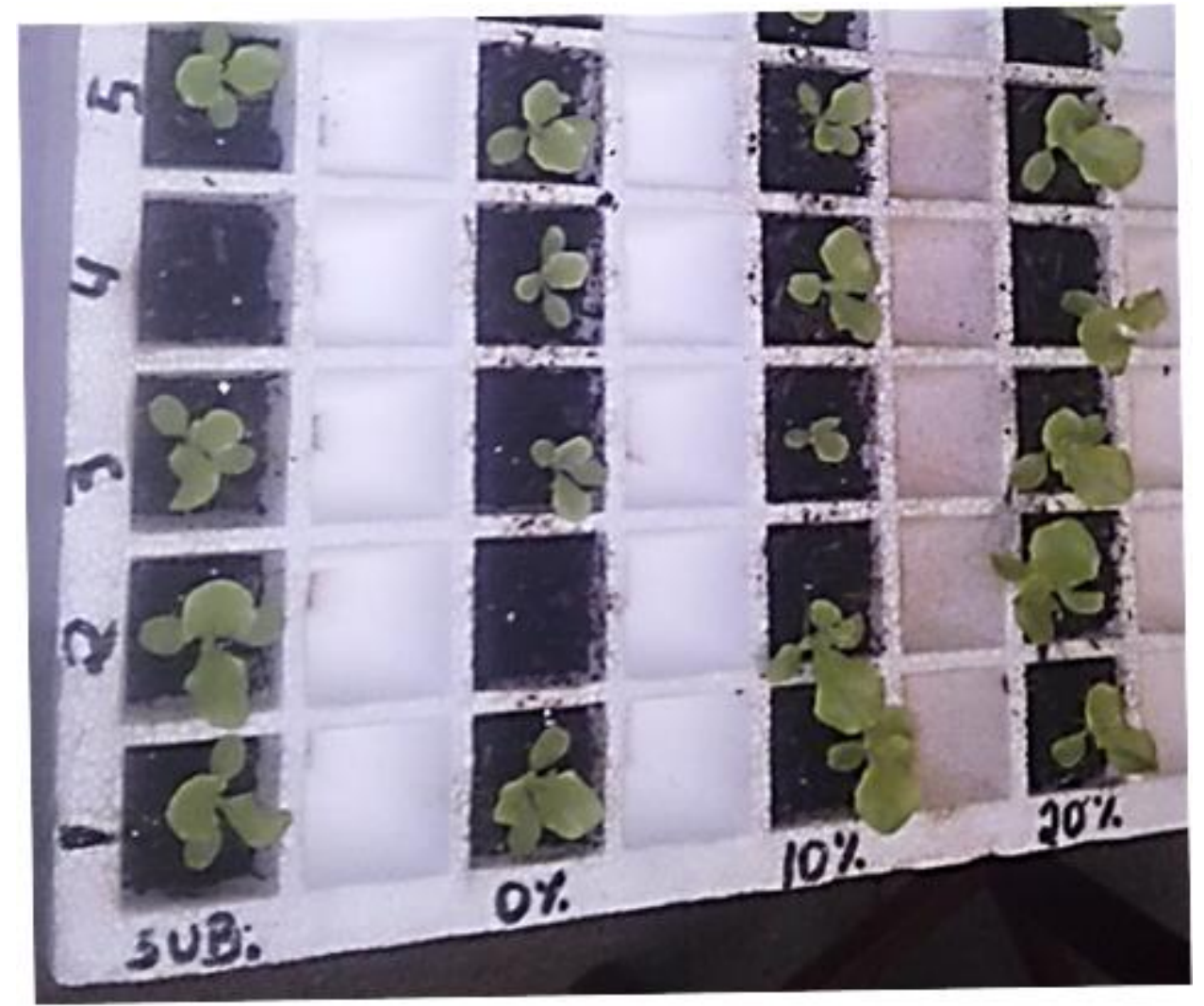

Figura 3. Desenvolvimento das mudas de hortaliça cultivadas com hidrogéis sintetizados com diferentes concentrações de nanoargila. 


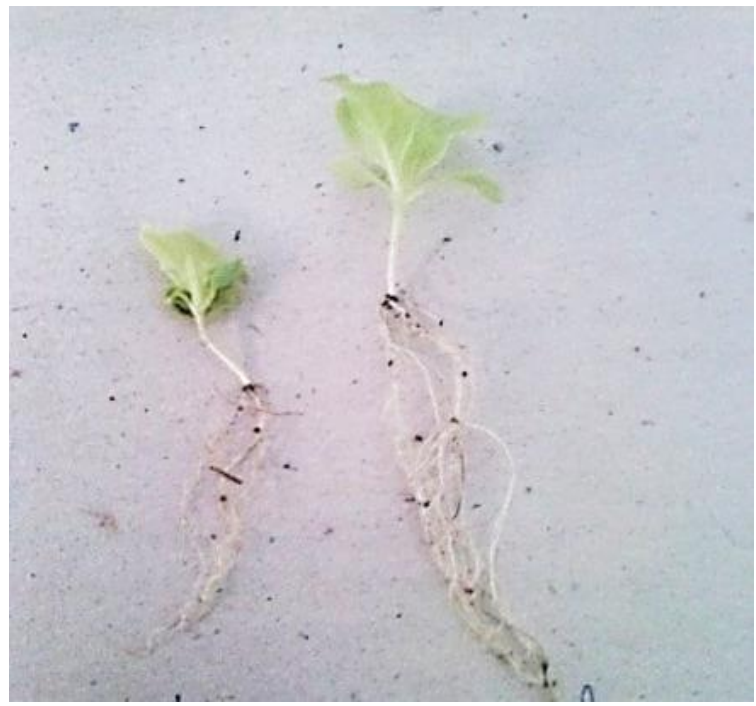

(a)

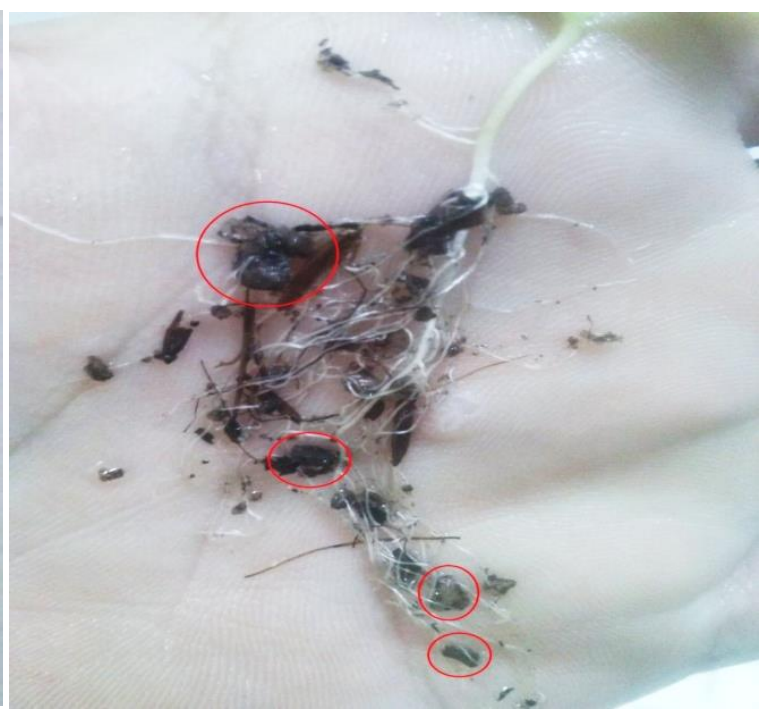

(b)

Figura 4. (a) Diferença da quantidade de raiz em relação ao substrato (controle) (esquerda) e bionanocompósito com 20\% de argila (direita), e (b) pequenas quantidades de bionanocompósito fixado na raiz da planta.

É provável que hidrogel fixado nas raízes das mudas, melhore a eficiência do uso da água, através de um maior contato da raiz com fonte de água que está disponível para as mudas, permitindo assim, melhores condições de sobrevivência e desenvolvimento da muda. Estes resultados são consistentes com os de Hillary et al. (2011), no qual os autores observaram que a aplicação de um polímero hidrorretentor no crescimento de um capim (Agrostisstolonifera) aumentou o desenvolvimento e a quantidade de raiz, formando algumas agregações dos fragmentos do hidrogel nas raízes. A aplicação de hidrogel de poliacrilamida na germinação de sementes de gramíneas australiana (Metallophyte) aumentou a porcentagem de germinação e desenvolvimento radicular, devido à liberação gradativa de água para as raízes da planta (GUTERRES et al., 2013). Hidrogel em contato com a raiz desempenha um papel importante na disponibilidade de água no sistema de cultivo.

Portanto, os bionanocompósitos estudados aqui foram aplicados em cultivos de alface devido a sua alta velocidade de germinação, o que traria resultados mais rápidos. No entanto, os autores acreditam que o ganho no custo-benefício seria maior na aplicação em mudas com valores agregados maiores e/ou baixa taxa de germinação, tais como, plantas nativas, frutíferas, ornamentais e aplicando diretamente em solos arenosos ou argilosos (onde os déficits hídricos e de nutrientes são maiores) e não diretamente nos substratos.

\section{CONCLUSÃO}

O uso do hidrogel e seus bionanocompósitos no substrato utilizado para a produção de mudas de alface permite concluir que a melhor quantidade de hidrogel de PAAm e CMC foi de $5 \%$ em relação ao substrato.

Cultura Agronômica, Ilha Solteira, v.26, n.1, p.82-94, 2017 
A presença de nanoargila cloisita- $\mathrm{Na}^{+}$na matriz do hidrogel proporciona resultados positivos em todos os parâmetros analisados referentes à produção das mudas. $\mathrm{O}$ bionanocompósito contendo $20 \%$ de nanoargila em sua matriz foi o que obteve melhores resultados.

Os resultados obtidos demonstram que os bionanocompósitos otimizam a produção, o desenvolvimento e qualidade das mudas desta hortaliça, evidenciando ser um produto promissor para a aplicação na agricultura.

\section{AGRADECIMENTOS}

À Embrapa, Unesp e aos órgãos de fomento CAPES, CNPq e Fapesp pelo apoio financeiro e concessão de bolsas de produtividade em pesquisa e de estudo.

\section{REFERÊNCIAS BIBLIOGRÁFICAS}

AKHTEEL, J.; MHMOOD, K.; MALIK, K. A.; MARDAN, A.; AHMAD, M.; IQBAL, M. M. Effects of hydrogel amendment an water storage of sandy loam and loam soils and seedling growth of barley, wheat and chickpea. Plant, Soil and Environment, Praga, v. 50, n. 10, p.463-469, 2004.

ALBUQUERQUE FILHO, J. A. C.; LIMA, V. L. A.; MENEZES, D.; AZEVEDO, C. A. V.; NETO, J. D.; SILVA JÚNIOR, J. G. Características vegetativas do coentro submetido a doses do polímero hidroabsorvente e lâminas de irrigação. Revista Brasileira de Engenharia Agrícola e Ambiental, Campina Grande, v. 13, n. 6, p.671-679, 2009.

AOUADA, F. A.; MUNIZ, E. C.; VAZ, C. M. P.; MATTOSO, L. H. C. Correlação entre parâmetros da cinética de intumescimento com características estruturais e hidrofílicas de hidrogéis de poliacrilamida e metilcelulose. Química Nova, São Paulo, v. 32, n. 6, p.14821490, 2009.

AZEVEDO, G. T. O. S.; SOUZA, A. M.; AZEVEDO, G. B.; CERQUEIRA, P. H. A. Enraizamento de miniestacas de eucalipto com diferentes doses de polímero hidroretentor incorporado ao substrato. Scientia Forestalis, Piracicaba, v. 43, n. 108, p.773-780, 2015.

AZEVEDO, T. L. F.; BERTONHA, A.; GONÇALVES, A. C. A. Uso de hidrogel na agricultura. Revista do Programa de Ciências Agro-Ambientais, Alta Floresta, v. 1, n. 1, p.23-31, 2002.

BARBOSA, T. C.; RODRIGUES, R. R.; COUTO, H. T. Z. Tamanho do recipiente e o uso de hidrogel no estabelecimento de mudas de espécies florestais nativas. Hoehnea, São Paulo, v. 40, n. 3, p.537-556, 2013.

BORTOlin, A.; AOUADA, F. A.; MATTOSO, L. H. C.; RIBEIRO, C. Nanocomposite PAAm/methylcellulose/montmorillonite hydrogel: Evidence of synergistic effects for the

Cultura Agronômica, Ilha Solteira, v.26, n.1, p.82-94, 2017 
slow release of fertilizers. Journal of Agricultural and Food Chemistry, Washington, v. 61, n. 31, p.7431-7439, 2013.

FAN, R.; LUO, J.; YAN, S.; ZHOU, Y.; ZHANG, Z. Effects of biochar and superabsorbent polymer on substrate properties and water spinach growth. Pedosphere, Beijing, v. 25, n. 5, p.737-748, 2015.

FONTENO, W. C.; BILDERBACK, T. E. Impact of hydrogel on physical properties of coarse-structured horticultural substrates. Journal of the American Society for Horticultural Science, Alexandria, v. 118, n. 2, p.217-222, 1993.

GUTERRES, J.; ROSSATO, L.; PDMENZKY, A.; DOLEY, D.; WHITTAKER, M.; SCHMIDT, S. Micron-size metl-bendung hydrogel particles improve germination and radicle elongation of Australian metallophyte grasses in mine waste rock and tailings. Journal of Hazardous Materials, Amsterdam, v. 248, n. 1, p.442-450, 2013.

HAFLE, O. M.; CRUZ, M. C. M.; RAMOS, P. S.; RAMOS, J. D.; RAMOS, V. A. Produção de mudas de maracujazeiro-doce através da estaquia utilizando polímeros hidrorretentor. Revista Brasileira de Ciências Agrárias, Recife, v. 3, n. 3, p.232-236, 2008.

HILLARY, A.; ORIKIRIZA, L.J.B.; OBUA, J.; KABASA, J.D.; WORBES, M.; HUTTERMANN, A. Hydrogel amendment to sandy soil reduces irrigation frequency and improves the biomass of Agrostis stolonifera. Agricultural Sciences, Hubei, v. 2, n. 4, p.544$550,2011$.

HUTTERMANN, A.; ZMORODI, M.; REISE, K. Addition of hydrogels to soil for prolonging the survival of Pinus halepensis seedlings subjected to drought. Soil and Tillage Research, Amsterdam, v. 50, n. 3, p.295-304, 1999.

LIU, F.; MA, H.; XING, S.; DU, Z.; MA, B.; JING, D. Effects of super-absorbent polymer on dry matter accumulation and nutrient uptake of Pinus pinaster container seedlings. Journal of Florest Research, London, v. 18, n. 3, p.220-227, 2012.

MAGUIRE, J. D. Speed of germination-aid in selection and evaluation for seedlings emergence and vigor. Crop Science, Madison, v. 2, n. 1, p.176-177, 1962.

MARQUES, P. A. A.; BARTOS, R. O. Uso de diferentes doses de hidrogel para produção de mudas de pimentão. Pesquisa Aplicada e Agrotecnologia, Londrina, v. 3, n. 2, p.39-48, 2010

MENDONÇA, T. G.; URBANO, V. R.; PERES, J. G.; SOUZA, C. F. Hidrogel como alternativa no aumento da capacidade de armazenamento de água no solo. Water Resources and Irrigation, Cruz das Almas, v. 2, n. 2, p.87-92, 2013.

MOREIRA, R. A.; RAMOS, J. D.; CRUZ. M. C. M; VILLAR, L.; HAFLE, O. M. Efeito de doses de polímero hidroabsorvente no enraizamento de estacas de amoreira. Revista Agrarian, Dourados, v. 3, n. 8, p.133-139, 2010.

Cultura Agronômica, Ilha Solteira, v.26, n.1, p.82-94, 2017 
NAVROSKI, M. C.; ARAUJO, M. M.; FIOR, C. S.; CUNHA, F. S.; BERGHETTI, A. L. P.; PEREIRA, M. O. Hydrogel enables use of reduction of irrigation and improves tee initial growth of Eucalyptus dunnii Maiden seedlings. Scientia Forestalis, Piracicaba, v. 43, n. 4, p.106-113, 2015.

SOUSA, G. T. O.; AZEVEDO, G. B.; SOUSA, J. R. L.; MEWS, C. L.; SOUZA, A. M. Incorporação de polímero hidroretentor no substrato de produção de mudas de Anadenanthera peregrina (L.) SPEG. Enciclopédia Biosfera, Goiânia, v. 9, n. 16, p.1270-1278, 2013. 